\title{
Association Between CLOCK Gene Variants and Restless Legs Syndrome in Koreans
}

\author{
Jae Eun Seo ${ }^{1,2 *}$, Ji Won Yeom ${ }^{1,2 *}$, Sehyun Jeon ${ }^{1,2}$, Chul-Hyun $\mathrm{Cho}^{2,3,4}$, \\ Seunghwa Jeong ${ }^{1,2}$, and Heon-Jeong Lee ${ }^{1,2} \bowtie$ \\ 'Department of Psychiatry, Korea University College of Medicine, Seoul, Republic of Korea \\ ${ }^{2}$ Chronobiology Institute, Korea University, Seoul, Republic of Korea \\ ${ }^{3}$ Department of Psychiatry, School of Medicine, Chungnam National University, Daejeon, Republic of Korea \\ ${ }^{4}$ Department of Psychiatry, Chungnam National University Sejong Hospital, Sejong, Republic of Korea
}

Objective Previous studies have suggested various causes of restless legs syndrome (RLS), including iron and dopamine concentrations in the brain. Genetic influences have also been reported in many studies. There is also a possibility that circadian clock genes may be involved because symptoms of RLS worsen at night. We investigated whether CLOCK and NPAS2 gene polymorphisms were associated with RLS.

Methods A total of 227 patients with RLS and 229 non-RLS matched controls were assessed according to the International Restless Legs Syndrome Study Group diagnostic criteria. Genotyping was performed using reverse transcription polymerase chain reaction and high-resolution melting curve analyses.

Results Although the genotype distributions of the CLOCK variants (rs1801260 and rs2412646) were not significantly different between patients with RLS and non-RLS controls, the allele frequencies of CLOCK rs1801260 showed marginally significant differences between the two groups $\left(\mathrm{X}^{2}=2.98, \mathrm{p}=0.085\right)$. Furthermore, there was a significant difference in the distribution of CLOCK haplotypes (rs1801260-rs2412646) between patients with RLS and non-RLS controls ( $\mathrm{p}=0.013)$. The distributions of allelic, genotypic, and haplotypic variants of NPAS2 (rs2305160 and rs6725296) were not significantly different between the two groups.

Conclusion Our results suggest that CLOCK variants may be associated with decreased susceptibility to RLS.

Psychiatry Investig 2021;18(11):1125-1130

Keywords CLOCK gene; Circadian rhythm; Restless legs syndrome.

\section{INTRODUCTION}

Restless legs syndrome (RLS), also called Willis-Ekbom disease, causes unpleasant or uncomfortable sensations in the legs and an irresistible urge to move them. RLS can cause severe sleep disturbance, depression, anxiety, and poor quality of life; it can also be a risk factor for cardiovascular disease..$^{1-3} \mathrm{~A}$ recent epidemiologic study reported that the prevalence of RLS in the

Received: September 13, 2021 Revised: October 1, 2021

Accepted: October 4, 2021

$\triangle$ Correspondence: Heon-Jeong Lee, MD, PhD

Department of Psychiatry, Korea University Anam Hospital, Korea University College of Medicine, 73 Goryeodae-ro, Seongbuk-gu, Seoul 02841, Republic of Korea

Tel: +82-2-920-6721, Fax: +82-2-6280-5810, E-mail: leehjeong@korea.ac.kr

*These authors contributed equally to this work.

(c) This is an Open Access article distributed under the terms of the Creative Commons Attribution Non-Commercial License (https://creativecommons.org/licenses/by$\mathrm{nc} / 4.0$ ) which permits unrestricted non-commercial use, distribution, and reproduction in any medium, provided the original work is properly cited.
Korean population is $7.5 \%$, but only $24.3 \%$ of those diagnosed with RLS are treated for their symptoms. ${ }^{4,5}$

Although the pathophysiological mechanism of RLS is still unknown, evidence suggests a genetic involvement in the disease. A family history of RLS has been reported in $60 \%$ of patients with idiopathic RLS, ${ }^{6,7}$ and linkage analyses in families have identified seven genetic loci associated with RLS: RLS1 on chromosome 12q12- 21, RLS2 on 14q13-21, RLS3 on 9p24p22, RLS4 on 2q33, RLS5 on 20p13, RLS6 on 19p13, and RLS7 on 16p12.1. ${ }^{8-14}$ Several gene variants have been found to be associated with RLS risk, most of which in genome-wide association studies (GWAS), with the strongest candidates being variants of PTPRD, BTBD9, MEIS1, and MAP2K5/SKOR1 genes in Caucasian populations. ${ }^{15-17}$

Among these genes, MEIS1 is the most likely cause of RLS in Caucasian populations ${ }^{18}$ but studies in Asia have shown a stronger link between BTBD9 or MAP2K5/SKOR1 genes. ${ }^{19,20}$ 
A GWAS of a Korean population reported that the UTRN gene showed a significant association with RLS. ${ }^{20}$ This suggests the possibility of racial differences in the genetic influences on RLS. One essential diagnostic characteristic of RLS is the presence of circadian variation in symptoms, and the diagnostic criteria of RLS also reflect this. However, the mechanisms underlying these circadian variations remain unknown. Because dopaminergic mechanisms seem to play a central role in the pathophysiology of RLS, changes in the circadian regulation of the central dopamine system or factors affecting it are likely to cause the worsening of symptoms during the nighttime. ${ }^{21}$ Because RLS severity varies with the circadian pattern, with the maximum number of occurrences in the late evening or at night, circadian genes can be candidate genes for RLS.

Although RLS exhibits clear circadian symptom fluctuations, circadian genes have not been reported to be associated with primary RLS in previous studies. In a study done by Kripke et al., ${ }^{22}$ CLOCK, TEF, and NR1D1 were found to be associated with periodic limb movement index, number of RLS diagnostic questions answered affirmatively, and reported frequency of RLS symptoms, respectively, when the possible confounding factor of apnea was minimized by selecting participants with apnea-hypopnea index $<15$. Such associations were not, however, observed when answering yes to all four diagnostic criteria or not was used for group determination. There have been studies on the association between circadian genes and primary and secondary RLS in special populations: $C L O C K, B T B D 9$, GNB3, and TH were associated with antipsychotic-induced RLS in Korean schizophrenia patients, and TEF was associated with sleep disturbances, including RLS symptoms, in Chinese Parkinson's disease patients. ${ }^{23,24}$ Overall, an association between circadian genes and primary RLS as a distinct diagnostic syndrome in the general population has not been thoroughly examined.

CLOCK, as a component of CLOCK:BMAL1 heterodimer, plays a major role in the transcriptional feedback loop generating circadian rhythm. NPAS2 is the paralog of CLOCK and can substitute for CLOCK. CLOCK genes are involved in the circadian rhythmicity of melatonin synthesis and secretion, and the significant differences of CLOCK gene variants in Korean schizophrenia patients with RLS were postulated to be the result of melatonin's circadian modulation. ${ }^{23,25}$ We hypothesized that the circadian rhythmicity of primary RLS is likewise under the control of circadian genes, including CLOCK and NPAS2, a functional substitute of $C L O C K$ in the suprachiasmatic nucleus, via melatonin modulation. ${ }^{26}$ Therefore, we investigated whether there was an association between circadian gene (CLOCK and NPAS2) polymorphisms and primary RLS.

\section{METHODS}

\section{Study participants}

All subjects were recruited from multiple centers, including the Korea University Hospital Sleep Clinic and two private sleep clinics in Seoul, South Korea. All subjects visited the sleep clinics because of insomnia. Sleep specialists reached a diagnosis based on the subject's signs and symptoms, medical and family histories, physical examinations, and test results. They also ruled out other conditions that may result in symptoms similar to those of RLS. Sex- and age-matched healthy controls were selected based on RLS symptom evaluation and medical and family histories. All subjects and controls were assessed using the International Restless Legs Syndrome Study Group (IRLSSG) diagnostic criteria. Finally, there were 227 patients with RLS and 229 non-RLS matched controls from the general population. Written informed consent was obtained from all study participants, including the patients with RLS and non-RLS matched controls, and approval was obtained from the Institutional Review Board (IRB) of Korea University Hospital (IRB No. IEC107014).

\section{Symptom assessment}

RLS was assessed using the IRLSSG diagnostic criteria. All subjects were asked about the following four diagnostic criteria for RLS: 1) urges to move their legs, 2) unpleasant sensations in their legs, 3) symptoms worsening during rest and relieved by movement, and 4) symptoms worsening in the evening or at night. ${ }^{27}$ Unpleasant sensations caused by other kinds of medical, surgical, or psychiatric problems were not considered to be symptoms of RLS. All the four essential diagnostic criteria had to be met for the subjects to be diagnosed with RLS.

Non-RLS-matched controls were recruited from the general population. Controls were also assessed using the IRLSSG diagnostic criteria to exclude RLS diagnosis. RLS symptom severity was assessed using the IRLSSG rating scale. ${ }^{28}$

\section{Genotyping}

A total of 456 participants were genotyped for this study. Blood was collected in 5-mL EDTA vacutainers (BD, Plymouth, $\mathrm{UK}$ ) and stored at $-80^{\circ} \mathrm{C}$ until genotyping. Genomic DNA was extracted using a blood DNA purification kit (Cosmo Genetech Co. Ltd., Seoul, Korea). After quality assessment with a NanoDrop spectrophotometer (NanoDrop Technologies, Wilmington, DE, USA), genotyping was performed using high-resolution melting (HRM) curve analysis. PCR was performed in a volume of $20 \mathrm{~mL}$ per reaction with a 96-well Bio-Rad CFX96 Real Time PCR system (Bio-Rad Laboratories, Hercules, CA, USA). Reaction mixtures included $1.5 \mathrm{~mL}$ of genomic DNA as a template, $1 \times$ Sso Fast EvaGreen SuperMix (Bio-Rad), 200 $\mathrm{mM}$ of each primer, and sterile $\mathrm{H}_{2} \mathrm{O}$. PCR primers for CLOCK 
and NPAS2 genes were as follows: CLOCK rs1801260 forward: 5'-GGGAAAGTTCCAGCAGTT-3', reverse: 5'-ATCCAGG CACCTAAAACAC-3'; rs2412646 forward: 5'-TGGAGTAA GTTGTTACACAGC-3', reverse: 5'-TGGGAAATTATAGTC AGAATTGGAA-3'; NPAS2 rs2305160 forward: 5'-GATTTG TGGGAACTTCTTGAG-3', reverse: 5'-ATGAGGACTGTT TGATGTGT-3'; and rs2305160 forward: 5'-ACTTCCCAGA CCTGTGAT-3', reverse: 5'-GCTTTACATCCATTCATTCC TTC-3'. The amplification protocol was started at $98^{\circ} \mathrm{C}$ for 3 min, followed by 39 cycles of $98^{\circ} \mathrm{C}$ for $10 \mathrm{~s}$ and $58^{\circ} \mathrm{C}$ for $20 \mathrm{~s}$. After an initial step of $95^{\circ} \mathrm{C}$ for $10 \mathrm{~s}$ and $65^{\circ} \mathrm{C}$ for $10 \mathrm{~s}$, melting curves were generated from $65^{\circ} \mathrm{C}$ to $95^{\circ} \mathrm{C}$ in increments of $0.3^{\circ} \mathrm{C} /$ cycle. Melting profiles were analyzed using the Bio-Rad Precision Melt software. The Hardy-Weinberg equilibrium test was performed to assess the goodness of fit of the data.

\section{Statistical analysis}

The Hardy-Weinberg equilibrium was tested using the $\chi^{2}$ test for goodness of fit. To compare the baseline characteristics between the patients with RLS and non-RLS controls, $\chi^{2}$ and ttests were performed for categorical variables and continuous variables, respectively. All analyses were performed using SPSS for Windows (SPSS, Chicago, IL, USA) and SNPAlyze (DYNACOM, Chiba, Japan). Haplotype analysis was performed using the SNPAlyze software. Differences were considered statistically significant at $p$ values less than 0.05 , and those less than 0.10 were considered marginally significant. Power calculations were performed using G*Power 3.1.4 (Dusseldorf, Germany). ${ }^{29}$

\section{RESULTS}

\section{Demographic and clinical features of the study participants}

There were no significant differences in age or sex ratio between patients with RLS and controls $\left(\chi^{2}=2.52, \mathrm{p}=0.113\right.$; $\mathrm{t}=$ $1.59, \mathrm{p}=0.112)$. The severity of the RLS symptoms evaluated using the IRLSSG Rating Scale was on average 22.16 \pm 8.20. Among the 227 patients with RLS, 58 had a family history of RLS in the first-degree relatives (23.60\%). Table 1 shows the demographic and clinical features of the study participants.

\section{Genotype distributions and allele frequencies of the CLOCK and NPAS2 genes}

No deviations from Hardy-Weinberg equilibrium were observed in any of the variants of CLOCK and NPAS2 genes between the patients with RLS and non-RLS controls. Table 2 shows the genotype distributions according to the general genetic model, dominant model, and recessive model, and allele frequencies of CLOCK and NPAS2 variants. Although the gen-
Table 1. Demographic and clinical features of study participants: patients with RLS and non-RLS controls

\begin{tabular}{lccc}
\hline & $\begin{array}{c}\text { Patients with RLS } \\
(\mathrm{N}=227)\end{array}$ & $\begin{array}{c}\text { Non-RLS controls } \\
(\mathrm{N}=229)\end{array}$ & $\mathrm{p}$ \\
\hline Female/male & $153 / 74$ & $138 / 91$ & 0.113 \\
Age, years & $49.45(15.74)$ & $47.21(14.21)$ & 0.112 \\
Family history & $58(25.55)$ & - & - \\
RLS severity* & $22.16(8.20)$ & - & - \\
\hline
\end{tabular}

Data are presented as the $\mathrm{N}(\%)$ or mean (SD). *assessed using the International RLS Study Group (IRLSSG) Rating Scale. RLS, restless legs syndrome

otype distributions (general genetic, dominant, and recessive models) of the two CLOCK variants (rs1801260 and rs2412646) were not significantly different between the patients with RLS and non-RLS controls, the allele frequencies of CLOCK rs1801260 were marginally significantly different between the two groups $\left(\chi^{2}=2.98, \mathrm{p}=0.085\right)$. The genotype distributions (general genetic, dominant, and recessive models) and allele frequencies of the two variants of NPAS2 (rs2305160 and rs6725296) did not show any significant differences between the two groups.

\section{Haplotype analysis}

Global haplotype analysis for the two variants of CLOCK (rs1801260-rs2412646) revealed a statistically significant difference in haplotype frequency between the patients with RLS and non-RLS controls (permutated $\mathrm{p}=0.013$ ) (Table 3). We did not perform NPAS2 gene haplotype analysis of the NPAS2 gene because there were no significant differences in the genotype and allele distributions between the two groups.

\section{DISCUSSION}

Typically, RLS symptoms appear and worsen during the evening and at night. Due to this characteristic diurnal variation in symptom intensity, many studies have suggested that RLS symptoms may be modulated by circadian rhythmicity. ${ }^{30-32}$ In addition, RLS has been reported to have a strong genetic component. ${ }^{33,34}$ Specifically regarding circadian rhythm genes, a study by Jung et al. ${ }^{23}$ found significant differences in the genotype and haplotype frequencies of CLOCK gene variants between patients with RLS and non-RLS controls in Korean patients with schizophrenia. In the present study, we investigated the association between RLS and CLOCK and NPAS2 polymorphisms in the general Korean population. We observed genetic associations only in the CLOCK gene, and significant differences in allele frequency and haplotype frequency between patients with RLS and non-RLS controls. The risk for RLS tended to be lower among those with the $\mathrm{G}$ allele of CLOCK rs1801260, and especially among those with the G-T haplotype of CLOCK 
(rs1801260-rs2412646). Therefore, our results suggest that these CLOCK gene variants may also have a protective effect against RLS, leading to decreased susceptibility to RLS.

The characteristic circadian rhythmicity of RLS indicates that
RLS may be under the influence of circadian genes, and such circadian control may be modulated through melatonin. The pathophysiology of RLS remains largely unknown. Dopamine dysfunction and iron deficiency in the brain are the most wide-

Table 2. Results of case-control association analysis of SNPs between patients with RLS and non-RLS controls

\begin{tabular}{|c|c|c|c|c|c|c|c|}
\hline & $\begin{array}{l}\text { RLS cases } \\
(\mathrm{N}=227)\end{array}$ & $\begin{array}{c}\text { Non-RLS controls } \\
(\mathrm{N}=229)\end{array}$ & p-value & & $\begin{array}{c}\text { RLS cases } \\
(\mathrm{N}=227)\end{array}$ & $\begin{array}{l}\text { Non-RLS controls } \\
(\mathrm{N}=229)\end{array}$ & $\mathrm{p}$-value \\
\hline CLOCK rs 1801260 & & & & CLOCK rs2412646 & & & \\
\hline Genotype & & & 0.232 & Genotype & & & 0.783 \\
\hline $\mathrm{A} / \mathrm{A}$ & $180(79.29)$ & $167(72.93)$ & & $\mathrm{C} / \mathrm{C}$ & $123(54.18)$ & $117(51.09)$ & \\
\hline $\mathrm{A} / \mathrm{G}$ & $44(19.38)$ & $56(24.45)$ & & $\mathrm{C} / \mathrm{T}$ & $88(38.77)$ & $96(41.92)$ & \\
\hline G/G & $3(1.32)$ & $6(2.62)$ & & $\mathrm{T} / \mathrm{T}$ & $16(7.05)$ & $16(6.99)$ & \\
\hline Dominant model & & & 0.703 & Dominant model & & & 0.883 \\
\hline $\mathrm{AA}$ & $180(79.30)$ & $167(72.93)$ & & $\mathrm{CC}$ & $123(54.18)$ & $117(51.09)$ & \\
\hline $\mathrm{AG}+\mathrm{GG}$ & $47(20.70)$ & $62(27.07)$ & & $\mathrm{TC}+\mathrm{TT}$ & $104(45.81)$ & $112(48.91)$ & \\
\hline Recessive model & & & 0.498 & Recessive model & & & 1.010 \\
\hline GG & $3(1.32)$ & $6(2.62)$ & & TT & $16(7.05)$ & $16(6.99)$ & \\
\hline $\mathrm{AA}+\mathrm{AG}$ & $224(98.68)$ & $223(97.38)$ & & $\mathrm{CC}+\mathrm{TC}$ & $211(92.95)$ & $213(93.01)$ & \\
\hline Allele & & & $0.085^{*}$ & Allele & & & 0.607 \\
\hline A & 404 (88.99) & $390(85.15)$ & & $\mathrm{C}$ & $334(73.57)$ & $330(72.05)$ & \\
\hline G & $50(11.01)$ & $68(14.85)$ & & $\mathrm{T}$ & $120(26.43)$ & $128(27.95)$ & \\
\hline NPAS2 rs2305160 & & & & NPAS2 rs6725296 & & & \\
\hline Genotype & & & 0.333 & Genotype & & & 0.858 \\
\hline $\mathrm{A} / \mathrm{A}$ & $9(3.96)$ & $12(5.24)$ & & $\mathrm{A} / \mathrm{A}$ & $7(3.08)$ & $8(3.49)$ & \\
\hline $\mathrm{A} / \mathrm{G}$ & $72(31.72)$ & $85(37.12)$ & & $\mathrm{A} / \mathrm{G}$ & $61(26.87)$ & $66(28.82)$ & \\
\hline $\mathrm{G} / \mathrm{G}$ & $146(64.32)$ & $132(57.64)$ & & $\mathrm{G} / \mathrm{G}$ & $159(70.04)$ & $155(67.68)$ & \\
\hline Dominant model & & & 0.755 & Dominant model & & & 0.896 \\
\hline GG & $146(64.32)$ & $132(57.64)$ & & GG & $159(70.04)$ & $155(67.68)$ & \\
\hline $\mathrm{AA}+\mathrm{AG}$ & $81(35.68)$ & $97(42.36)$ & & $\mathrm{AA}+\mathrm{AG}$ & $68(29.96)$ & $74(32.31)$ & \\
\hline Recessive model & & & 0.747 & Recessive model & & & 0.879 \\
\hline $\mathrm{AA}$ & $9(3.96)$ & $12(5.24)$ & & $\mathrm{AA}$ & $7(3.08)$ & $8(3.49)$ & \\
\hline $\mathrm{AG}+\mathrm{GG}$ & $218(96.03)$ & $217(94.76)$ & & $\mathrm{AG}+\mathrm{GG}$ & $220(96.91)$ & $221(96.51)$ & \\
\hline Allele & & & 0.146 & Allele & & & 0.580 \\
\hline A & $90(19.82)$ & $109(23.19)$ & & A & $75(16.52)$ & $82(17.90)$ & \\
\hline G & $364(80.18)$ & $349(74.25)$ & & G & $379(83.48)$ & $376(82.10)$ & \\
\hline
\end{tabular}

Data are presented as $\mathrm{N}(\%) .{ }^{*} 0.05<\mathrm{p}<0.1$. SNP, single nucleotide polymorphism; RLS, restless legs syndrome

Table 3. Haplotype analysis of CLOCK rs1801260-rs2412646 and comparison between patients with RLS and non-RLS controls

\begin{tabular}{ccccc}
\hline CLOCK haplotype & Overall & Non-RLS controls & Patients with RLS & Permutation p-value \\
\hline A-C & 0.6126 & 0.6049 & 0.6256 & 0.520 \\
A-T & 0.2581 & 0.2467 & 0.2643 & 0.536 \\
G-C & 0.1155 & 0.1157 & 0.1101 & 0.795 \\
G-T & 0.0139 & 0.0328 & $9.94 \mathrm{E}-09$ & $<0.001$ \\
\hline Select locus & \multicolumn{4}{c}{ Permutation p-value } \\
\hline CLOCK rs1801260/CLOCK rs2412646 & \multicolumn{4}{c}{0.013} \\
\hline
\end{tabular}

RLS, restless legs syndrome 
ly accepted pathways for understanding RLS. ${ }^{35}$ Michaud et al..$^{31}$ found that melatonin secretion increased just before sensory and motor symptoms in patients with RLS. Melatonin, with its known inhibitory effect on dopamine release, ${ }^{36}$ may be the key element in disentangling the underlying mechanism of circadian rhythmicity in RLS. Often used as a chronotherapeutic agent for various sleep-wake disorders, melatonin worsened motor symptoms in RLS patients when administered exogenously, possibly by further decreasing dopaminergic function. ${ }^{37}$ Exogenous administration of melatonin in the evening also causes phase advance, ${ }^{38}$ increasing melatonin levels earlier during the day, potentially leading to earlier manifestation of RLS symptoms. This may uncover previously unrecognized symptoms by introducing symptoms before the initiation of sleep. Therefore, it is of great importance to assess the role of melatonin in the circadian rhythmicity of RLS.

At the genetic level, circadian genes may be one candidate that broadens our understanding of the pathophysiology of RLS. Not only do RLS symptoms have circadian rhythmicity, but melatonin is also under circadian control. Furthermore, melatonin formation is directly affected by the CLOCK gene. ${ }^{25}$ The CLOCK gene, located on chromosome $4 \mathrm{q} 12$, is a classic circadian gene in the transcriptional-translational feedback loop of the circadian rhythm. The association between CLOCK polymorphisms and melatonin circadian rhythm is yet to be fully investigated. In postmenopausal Caucasian women, the $\mathrm{G}$ allele of CLOCK rs1801260 was found to be associated with higher nocturnal melatonin levels, lower morning melatonin levels, and the opposite pattern was seen with the A allele. ${ }^{39}$ However, in the same study, no significant differences were observed in the Asian population..$^{39}$ Our results suggest a protective effect of the G allele of CLOCK rs 1801260 and especially the G-T haplotype of CLOCK (rs1801260-rs2412646), and this effect may be mediated by melatonin circadian rhythmicity. To the best of our knowledge, there is no study on the association between CLOCK polymorphisms and melatonin circadian rhythm in the Korean population.

Our study has the following limitations. First, the allele frequencies of CLOCK rs 1801260 showed marginally significant difference between the patients with RLS and non-RLS controls. Such difference of marginal significance should be carefully considered when interpreting the results. It may be due to a limited sample size, or it may indicate the role of the specific SNP in genetic influence. Since the G-T haplotype of CLOCK (rs1801260-rs2412646) resulted in much significant difference, the $G$ allele that showed only marginal significance when examined alone may exert its full effect as a component of a specific haplotype. Second, our sample size may limit the generalization of the study results. We had a power of 0.47 and 0.57 to detect an effect size of 0.10 in genotype and allele carrier fre- quencies, respectively. Further studies with a larger sample size may be needed for replication of these results. Third, population stratification bias cannot be ruled out. However, this possibility is unlikely due to the relatively highly homogeneous nature of the Korean population. ${ }^{40}$ Fourth, a possible mechanism underlying the association between CLOCK polymorphisms and RLS symptoms would have been more clearly revealed if melatonin circadian rhythms were also assessed by measuring melatonin levels. Future studies on the role of CLOCK polymorphisms and their relationship with melatonin circadian rhythm are warranted to further elucidate the pathophysiology of RLS and the contribution of circadian genes.

In conclusion, CLOCK polymorphisms may be associated with RLS in the Korean population. The non-RLS controls had significantly higher frequencies of the G allele of CLOCK rs1801260 and the G-T haplotype of CLOCK (rs1801260rs2412646) than those of the patients with RLS. In other words, the $\mathrm{G}$ allele of CLOCK rs1801260 and especially the G-T haplotype of CLOCK (rs1801260-rs2412646) may have protective effects against the development and progression of RLS. We also postulated that this possible preventive effect may be related to the circadian rhythm of melatonin. Further research is needed to fully examine the relationship between circadian rhythm genes and the pathophysiology of RLS.

\section{Availability of Data and Material}

The datasets generated or analyzed during the study are available from the corresponding author on reasonable request.

\section{Conflicts of Interest}

Heon-Jeong Lee, a contributing editor of the Psychiatry Investigation, was not involved in the editorial evaluation or decision to publish this article. All remaining authors have declared no conflicts of interest.

\section{Author Contributions}

Conceptualization: Heon-Jeong Lee. Data curation: Seunghwa Jeong, Chun-Hyun Cho. Formal analysis: Heon-Jeong Lee. Funding acquisition: Heon-Jeong Lee. Investigation: Jae Eun Seo, Seunghwa Jeong. Methodology: Ji Won Yeom, Seunghwa Jeong, Sehyun Jeon. Project administration: Heon-Jeong Lee. Resources: Heon-Jeong Lee. Software: Jae Eun Seo, Ji Won Yeom, Seunghwa Jeong, Sehyun Jeon. Supervision: Heon-Jeong Lee. Validation: Heon-Jeong Lee. Visualization: Jae Eun Seo, Ji Won Yeom. Writing_original draft: Jae Eun Seo, Ji Won Yeom. Writing_review \& editing: Heon-Jeong Lee.

\section{ORCID iDs}

Jae Eun Seo

Ji Won Yeom Sehyun Jeon

Chul-Hyun Cho

Seunghwa Jeong

Heon-Jeong Lee

https://orcid.org/0000-0002-6167-5218

https://orcid.org/0000-0003-0038-2101 https://orcid.org/0000-0002-6594-6556 https://orcid.org/0000-0002-1663-9680 https://orcid.org/0000-0003-3850-9243 https://orcid.org/0000-0002-9560-2383

\section{Funding Statement}

This study was supported by the Korea Health 21 R\&D Project funded by the National Research Foundation of Korea (2017M3A9F1031220 and 2019R1A2C2084158). 


\section{REFERENCES}

1. Cho CH, Kim L, Lee HJ. Individuals with restless legs syndrome tend to have severe depressive symptoms: findings from a community-based cohort study. Psychiatry Investig 2017;14:887-893.

2. Zhuang S, Na M, Winkelman JW, Ba D, Liu CF, Liu G, et al. Association of restless legs syndrome with risk of suicide and self-harm. JAMA Netw Open 2019;2:1-11.

3. Winter AC, Schü M, Glynn RJ, Buring JE, Gaziano JM, Berger K, et al. Restless legs syndrome and risk of incident cardiovascular disease in women and men: prospective cohort study. BMJ Open 2012;2:e000866.

4. Cho SJ, Hong JP, Hahm BJ, Jeon HJ, Chang SM, Cho MJ, et al. Restless Legs Syndrome (RLS) is a common sensorimotor disorder in Western countries with estimated prevalence between $5 \%$ and $10 \%$ of the general population. Sleep 2009;32:1069-1076.

5. Park YM, Lee HJ, Kang SG, Choi HS, Choi JE, Cho JH, et al. Prevalence of idiopathic and secondary restless legs syndrome in Korean Women. Gen Hosp Psychiatry 2010;32:164-168.

6. Champion D, Pathirana S, Flynn C, Taylor A, Hopper JL, Berkovic SF, et al. Growing pains: twin family study evidence for genetic susceptibility and a genetic relationship with restless legs syndrome. Eur J Pain 2012;16:1224-1231.

7. Winkelmann J, Wetter TC, Collado-Seidel V, Gasser T, Dichgans M, Yassouridis A, et al. Clinical characteristics and frequency of the hereditary restless legs syndrome in a population of 300 patients. Sleep 2000;23:597-602.

8. Bonati MT, Ferini-Strambi L, Aridon P, Oldani A, Zucconi M, Casari G. Autosomal dominant restless legs syndrome maps on chromosome 14q. Brain 2003;126:1485-1492.

9. Chen S, Ondo WG, Rao S, Li L, Chen Q, Wang Q. Genomewide linkage scan identifies a novel susceptibility locus for restless legs syndrome on chromosome 9p. Am J Hum Genet 2004;74:876-885.

10. Desautels A, Turecki G, Montplaisir J, Sequeira A, Verner A, Rouleau GA. Identification of a major susceptibility locus for restless legs syndrome on chromosome 12q. Am J Hum Genet 2001;69:1266-1270.

11. Kemlink D, Plazzi G, Vetrugno R, Provini F, Polo O, Stiasny-Kolster K, et al. Suggestive evidence for linkage for restless legs syndrome on chromosome 19p13. Neurogenetics 2008;9:75-82.

12. Levchenko A, Montplaisir JY, Asselin G, Provost S, Girard SL, Xiong L, et al. Autosomal-dominant locus for restless Legs syndrome in FrenchCanadians on chromosome 16p12.1. Mov Disord 2008;24:40-50.

13. Levchenko A, Provost S, Montplaisir JY, Xiong L, St-Onge J, Thibodeau $\mathrm{P}$, et al. A novel autosomal dominant restless legs syndrome locus maps to chromosome 20p13. Neurology 2006;67:900-901.

14. Pichler I, Marroni F, Volpato CB, Gusella JF, Klein C, Casari G, et al. Linkage analysis identifies a novel locus for restless legs syndrome on chromosome $2 \mathrm{q}$ in a South Tyrolean population isolate. Am J Hum Genet 2006;79:716-723.

15. Schormair B, Kemlink D, Roeske D, Eckstein G, Xiong L, Lichtner P, et al. PTPRD (protein tyrosine phosphatase receptor type delta) is associated with restless legs syndrome. Nat Genet 2008;40:946-948.

16. Stefansson H, Rye D, Hicks A, Petursson H, Ingason A, Thorgeirsson $\mathrm{T}$, et al. A genetic risk factor for periodic limb movements in sleep. N Engl J Med 2007;357:639-64.

17. Winkelmann J, Schormair B, Lichtner P, Ripke S, Xiong L, Jalilzadeh S, et al. Genome-wide association study of restless legs syndrome identifies common variants in three genomic regions. Nat Genet 2007;39: 1000-1006.

18. El Gewely M, Welman MDS, Xiong L, Yin S, Catoire HDS, Rouleau G, et al. Reassessing GWAS findings for the shared genetic basis of insomnia and restless legs syndrome. Sleep 2018;41:1-6.

19. Li G, Tang H, Wang C, Qi X, Chen J, Chen S, et al. Association of BTBD9 and MAP2K5/SKOR1 with restless legs syndrome in Chinese population. Sleep 2017;40.

20. Cho CH, Choi JH, Kang SG, Yoon HK, Park YM, Moon JH, et al. A genome-wide association study identifies UTRN gene polymorphism for restless legs syndrome in a Korean population. Psychiatry Investig 2017;14:830-838.

21. Garcia-Borreguero D, Serrano C, Larrosa O, Granizo JJ. Circadian effects of dopaminergic treatment in restless legs syndrome. Sleep Med 2004;5:413-420.

22. Kripke DF, Shadan FF, Dawson A, Cronin JW, Jamil SM, Grizas AP, et al. Genotyping sleep disorders patients. Psychiatry Investig 2010;7:3642.

23. Jung JS, Lee HJ, Cho CH, Kang SG, Yoon HK, Park YM, et al. Association between restless legs syndrome and CLOCK and NPAS2 gene polymorphisms in schizophrenia. Chronobiol Int 2014;31:838-844.

24. Hua P, Liu W, Zhao Y, Ding H, Wang L, Xiao H. Tef polymorphism is associated with sleep disturbances in patients with Parkinson's disease. Sleep Med 2012;13:297-300.

25. Borjigin J, Zhang LS, Calinescu AA. Circadian regulation of pineal gland rhythmicity. Mol Cell Endocrinol 2012;349:13-19.

26. DeBruyne JP, Weaver DR, Reppert SM. CLOCK and NPAS2 have overlapping roles in the suprachiasmatic circadian clock. Nat Neurosci 2007;10:543-545.

27. Allen RP, Picchietti D, Hening WA, Trenkwalder C, Walters AS, Montplaisi J, et al. Restless legs syndrome: Diagnostic criteria, special considerations, and epidemiology. A report from the restless legs syndrome diagnosis and epidemiology workshop at the National Institutes of Health. Sleep Med 2003;4:101-119.

28. Horiguchi J, Hornyak M, Voderholzer U, Kryger M, Skomrow R, Lipinski JF, et al. Validation of the International Restless Legs Syndrome Study Group rating scale for restless legs syndrome. Sleep Med 2003;4: 121-132.

29. Erdfelder E, FAul F, Buchner A, Lang AG. Statistical power analyses using $\mathrm{G}^{*}$ Power 3.1: tests for correlation and regression analyses. Behav Res Methods 2009;41:1149-1160.

30. Baier PC, Trenkwalder C. Circadian variation in restless legs syndrome. Sleep Med 2007;8:645-650.

31. Michaud M, Dumont M, Selmaoui B, Paquet J, Fantini ML, Montplaisir J. Circadian rhythm of restless legs syndrome: relationship with biological markers. Ann Neurol 2004;55:372-380.

32. Odrcich M, Bailey JM, Cahill CM, Gilron I. Chronobiological characteristics of painful diabetic neuropathy and postherpetic neuralgia: Diurnal pain variation and effects of analgesic therapy. Pain 2006;120: 207-212.

33. Jiménez-Jiménez FJ, Alonso-Navarro H, García-Martín E, Agúndez JAG. Genetics of restless legs syndrome: an update. Sleep Med Rev 2018;39:108-121.

34. Didriksen M, Nawaz MS, Dowsett J, Bell S, Erikstrup C, Pedersen OB, et al. Large genome-wide association study identifies three novel risk variants for restless legs syndrome. Commun Biol 2020;3:703.

35. Guo S, Huang J, Jiang H, Han C, Li J, Xu X, et al. Restless legs syndrome: From pathophysiology to clinical diagnosis and management. Front Aging Neurosci 2017;9:171.

36. Zisapel N. Melatonin - dopamine interactions: from basic neurochemistry to a clinical setting. Cell Mol Neurobiol 2002;21:605-616.

37. Whittom S, Dumont M, Petit D, Desautels A, Adam B, Lavigne G, et al. Effects of melatonin and bright light administration on motor and sensory symptoms of RLS. Sleep Med 2010;11:351-355.

38. Lewy A. Clinical implications of the melatonin phase response curve. J Clin Endocrinol Metab 2010;95:3158-3160.

39. Semenova NV, Madaeva IM, Bairova TA, Zhambalova RM, Sholokhov LF, Kolesnikova LI. Association of the melatonin circadian rhythms with clock 3111T/C gene polymorphism in Caucasian and Asian menopausal women with insomnia. Chronobiol Int 2018;35:1066-1076.

40. Han GR, Lee YW, Lee HL, Kim SM, Ku TW, Kang IH, et al. A Korean population study of the nine STR loci FGA, VWA, D3S1358, D18551, D21S11, D8S1179, D7S820, D13S317 and D5S818. Int J Legal Med 2000;114:41-44. 